\title{
IMAGEM, PODER E DOENÇA: O CASO DO PREsidente Hugo ChÁvez NA TElesur
}


IMAGEM, PODER E DOENÇA: O CASO DO PRESIDENTE HuGO CHÁVEZ NA TELESUR

Resumo:

O texto reflete sobre o modo como a imagem de um governante é construída pela mídia em situações de enfermidades, de maneira especial, considerando o exercício do poder e as relações que estabelece. Para tanto, problematiza conceitos como a personificação do poder, os espaços midiáticos e sua interdependência com a esfera política. Ainda, utilizando algumas notícias ilustra as teorizações através do episódio com Hugo Chávez, que teve câncer diagnosticado e divulgado em junho de 2011.

Palavras chave: Poder; Imagem; Enfermidade; Hugo Chávez; Portal TeleSUR.

IMAGE, POWER AND DISEASE: THE CASE Of THE PRESIDENTE HUGO CHÁVEZ ON TELESUR

Abstract:

The text reflects about how the image of a ruler it's constructed by the media in situations of illness, specially, considering the exercise of power and the establishing relations. For this purpose, it discusses concepts such as embodiment of power, media spaces and your interdependence with a political sphere. Also, using some news illustrating the theories through the episode Hugo Chávez, who had cancer diagnosed and reported in Jun, 2011.

Keywords: Power; Image; Disease; Hugo Chávez; TeleSur Portal

IMAGEN, PODER Y ENFERMEREDAD: EL CASO DEL PRESIDENTE HUGO CHÁVEZ EN LA TELESUR

Resumen:

El texto reflete sobre el modo como la imagen de un gobernante es construida por los medios en situaciones de enfermedades, de manera especial, considerando el ejercicio del poder y las relaciones que establece. Para tanto, problematiza conceptos como la personificación del poder, los espacios mediáticos y su interdependencia con la esfera política. Aún, utilizando algunas noticias ilustra las teorizaciones por medio del episodio con Hugo Chávez, que tubo cáncer diagnosticado y divulgado en junio de 2011.

Palabras Clave Poder; Imagen; Enfermedad; Hugo Chávez; Portal TeleSUR 


\section{INTRODUÇÃO}

E por aí vai o herói. Com seus trabalhos. Como Hércules. Ou melhor suas funções. Pois esse monstro sagrado desempenha um tríplice ofício: ele faz o espetáculo, proporciona o sonho e confere a certeza (Roger-Gérard Schwartzenberg).

O texto busca problematizar os debates e teorizações desenvolvidos na disciplina "Comunicação, Política e Sociedade", aproximando conceitos e autores de referência, do objeto imediato da pesquisa de mestrado², o sistema comunicativo TeleSUR ${ }^{3}$. Para tanto, busca refletir sobre a maneira como a imagem de um governante é construída frente a situações de enfermidades, principalmente, considerando o exercício do poder e as relações que estabelece.

De modo específico, assinala as elaborações do portal TeleSUR no que tange às alterações na saúde do presidente venezuelano, Hugo Chávez, e ao tratamento empreendido em Cuba, nos últimos dois meses. Tem as reflexões ancoradas em questionamentos como que implicações uma enfermidade traz à imagem de um governante como Hugo Chávez? O que ocorre, midiaticamente, quando um sujeito público é acometido por uma doença? De que maneira esse sujeito pode impor e manter uma representação de si que capte a atenção do público? O que reproduzir e o que omitir nesses casos? E o poder, em suas relações e exercícios, como fica?

As caracterizações são realizadas a partir das primeiras informações divulgadas, referentes à intervenção cirúrgica, em 10 de junho de 2011, e à confirmação do tumor cancerígeno, no dia 30 daquele mês, observando se o governo, de alguma maneira, utilizou-se do sistema comunicativo TeleSUR para criar ou não uma agenda sobre os referidos acontecimentos. Além disso, mostra-se necessário considerar outros espaços midiáticos e a maneira como foram desenvolvidas especulações acerca da gravidade da situação, do real estado do presidente e dos possíveis efeitos na política venezuelana.

Ainda, o artigo pretende ponderar sobre as inter-relações entre sociedade, comunicação e política, pensando a doença como algo da esfera privada que toma o espaço público em determinadas situações, e a imagem do governante que é construída, em tais circunstâncias, pela mídia. Nesse sentido, importa enfatizar que a construção da imagem pública não pode ser pensada

1Ministrada pela professora Doutora Maria Helena Weber, foi cursada durante o primeiro semestre de 2011, na Universidade Federal do Rio Grande do Sul - UFRGS, através de convênio entre as instituiçõos.

2Orientada pelo professor Doutor Alberto Efendy Maldonado Gómez de la Torre.

3Organizando-se como um espaço comunicacional voltado à América Latina e seguindo princípios da Revolução Bolivariana, é resultado de um projeto mais amplo do atual governo da Venezuela que busca melhorar as relações entre os povos latino-americanos, por meio de uma comunicação diferenciada que enfatize as informações da região e valorize suas culturas. Disponível em: http://www.telesurtv.net/ 
apenas no âmbito da esfera midiática, mas sim, no sentido de um somatório em que atuam, por exemplo, discursos do governo, dos partidos, do próprio sujeito, entre outros elementos dessa constituição.

Com relação a essa perspectiva, do caso analisado importa destacar os discursos que são proferidos por Chávez, a partir de seu ponto de vista sobre as coisas ao redor e sobre ele mesmo. Além de fazer uso contínuo de comunicados e pronunciamentos, o presidente ocupa espaços midiáticos em que pode se manifestar e entrar em contato direto (ou menos mediado) com seu povo.

\section{PROBLEMATIZAÇÕES INICIAIS: ACERCANDO-SE DA REFLEXÃO}

Inicialmente, convém trazer alguns pontos do objeto proposto e dessa relação instituída entre sociedade, comunicação e política. Nesse sentido, pode-se colocar o que Schwartzenberg (1978, p. 165) chama de "reciprocidade de boas maneiras", na qual a imprensa promove a personalização do poder, e os políticos cotejam a imprensa. De acordo com Weber (2000), seria essa interdependência absoluta entre mídia e política, tornada ainda mais evidente na contemporaneidade.

Não há como imaginar a política sem visibilidade, sem essas redes de comunicação midiática criando reconhecimento de ações, sujeitos e instituições, fiscalizando e cobrando essas instâncias, atravessando Estado e sociedade, dando voz e espaço a ambos (mesmo que com intensidades, frequências e objetivos diferentes), reforçando ideias, temas, movimentos e posições, possibilitando a constituição e manutenção das relações sociais.

Assim também, a mídia necessita da política e das agitações constantes que essa esfera apresenta, conforme aponta Gomes (2004). Além da importância enquanto fonte de informação, pauta e material noticioso, existe uma dependência financeira, de investimentos do governo em verbas, como em propaganda. Somado a isso, pode-se colocar que o poder da mídia está na capacidade de difundir outros poderes, de visibilizar e legitimar outros discursos que não apenas os seus.

Com relação a esses fatores, um aspecto que chama a atenção e instiga a presente problematização é o uso que Hugo Chávez faz da comunicação e a consciência que possui sobre a importância desses canais. Por exemplo, desde 23 de maio de 1999 apresenta o programa radiofônico Alô presidente ${ }^{4}$, que começou a ser retransmitido também pela televisão, em 27 de agosto de 2000, ou a partir do dia 28 de abril de 2010, figurando ativamente com uma conta no Twitter ${ }^{5}$. Inclusive o 24 de julho de 2005, data da primeira transmissão da Tele-

40 programa é transmitido pela TeleSUR e possui uma página, disponível no endereço eletrônico <http://www.alopresidente.gob.ve/>.

50 endereço é $<$ twitter.com/chavezcandanga $>$. 
SUR, enquanto emissora de televisão, em Caracas, traz a marca comunicativa estratégica de Chávez, naquele dia foi comemorado o aniversário de 222 anos de nascimento do líder libertador Simon Bolívar.

Com relação às características do presidente e o modo como elas se estabelecem enquanto próprias de sua figura, Schwartzenberg (1978, p. 4) elucida o conhecimento e reconhecimento através da imagem, que "cria ou consolida a notoriedade ao servir de símbolo visível ou tangível. Quando suficientemente caracterizada e individualizada, a imagem capta o interesse do público. O perfil, suficientemente trabalhado, prende sua atenção". Sendo assim, serve de rótulo, indicando particularidades (reais ou supostas) e performances específicas de um ou de outro "produto" ou "marca" políticos.

Além disso, a opção pelo caso desse presidente para elucidar as teorizações ${ }^{6}$ se deve às contribuições para a investigação que vem sendo desenvolvida, também pela atualidade da manifestação, aparecendo nos dois últimos meses, e pelo modo peculiar como costuma ser representado nas mídias. Muito antes desse cenário de enfermidade se delinear, Maringoni (2004) relatava a complexidade de procurar compreender o fenômeno Chávez, ainda mais considerando as mudanças nas características do governo (como a administração pública e o programa econômico), e os inúmeros ataques advindos de setores historicamente favorecidos da sociedade venezuelana (por exemplo, o que culminou na tentativa de golpe em 2002).

Considerando esse ator principal, a disputa que trava com os outros atores e como faz sua própria comunicação, no caso das posturas do governante venezuelano, podem ser elucidados alguns aspectos do conceito, ainda confuso e polêmico, de marketing político. A noção auxilia na compreensão dos inúmeros elementos (não apenas a mídia, nem tampouco somente a praça) que, engendrados, constituem a política e, principalmente, definem seus rumos.

Para Almeida (2002, p. 20), “a utilização de técnicas do marketing político é imprescindível na política contemporânea, independentemente do caráter social e político-ideológico das forças políticas em jogo". Contudo, o uso que se faz dessas técnicas não leva necessariamente à despolitização da política. $O$ autor afirma ainda que, se o tratamento comercial das candidaturas é inevitável, a esquerda pode construir uma lógica contra-hegemônica, apresentar um caráter diferente à propaganda partidária

A partir dessa perspectiva, pode-se pensar na atuação que o presidente Hugo Chávez faz dos espaços midiáticos que dispõe para, por seus meios, contribuir com a construção da sua própria imagem pública. Todavia, importa ponderar sobre aquilo que foge ao controle dos discursos programáticos; um acontecimento que extravasa os limites que lhe seriam permitidos e ocupa

6Recentemente, com relação a manifestações de enfermidades, pode-se mencionar o presidente do Paraguai, Fernando Lugo, e a própria presidenta do Brasil, Dilma Rousseff (na época, ministra-chefe da Casa Civil).Ambos tiveram o câncer linfático diagnosticado e passaram por tratamentos que incluíram sessões de quimioterapia. 
espaços de outra ordem; situações que não deveriam estar em determinado lugar, mas se colocam, mesmo contra a vontade; o inesperado, a crise, o fator surpresa pondo em risco tudo que fora minuciosamente planejado. É o caso da doença que acometeu o Chefe de Estado venezuelano.

\section{PERSONIFICAÇÃO DO PODER: O CARISMA CONFRONTADO PELA DOENÇA}

Resgatando a definição apresentada por Bobbio et al (2002, p. 933), "em seu significado mais geral, a palavra Poder designa a capacidade ou a possibilidade de agir, de produzir efeitos". Ao especificar o sentido desse poder no âmbito social, percebe-se uma precisão que assinala a concepção na capacidade geral de agir e a capacidade de determinação do comportamento de um homem sobre os demais. Tal aspecto aponta para o caráter relacional do poder, segundo o qual, como fenômeno social, trata-se de uma relação?.

A partir de teorizações sobre o poder na sociedade em rede, Castells (2010, p. 33, tradução nossa) afirma a importância de tal noção no tecido social e apresenta a concepção segundo a qual "o poder é a capacidade relacional que permite a um ator social influir de forma assimétrica nas decisões de outros atores sociais de modo que se favoreçam a vontade, os interesses e os valores do ator que tem o poder" 8 . O autor também assinala as possibilidades de exercício do poder por meio da coerção (ou da possibilidade de sua prática) e/ou pela construção de significados nos discursos através dos quais os atores sociais guiam suas ações.

Nessa direção, Bourdieu (2000, p. 8) coloca um modo de dominação relacionado ao poder simbólico, em que esses discursos também dependem de uma crença dos sujeitos no que está sendo proposto. Esse poder invisível, como assinala o autor, "só pode ser exercido com a cumplicidade daqueles que não querem saber que lhe estão sujeitos ou mesmo que o exercem", por meio de sistemas estruturados, símbolos que são instrumentos estruturados e estruturantes de conhecimento e comunicação. Os sistemas simbólicos atuam na integração social e cumprem uma função política de instrumentos de imposição ou de legitimação da dominação, basicamente envolvida na busca de cada classe pelo estabelecimento da definição do mundo social que mais lhe interessa.

\footnotetext{
7 Bobbio et al (2002) afirmam ser essa uma relação triádica, pois, além de especificar a pessoa ou grupo quedetém o poder e a pessoa ou grupo que a ele está sujeito, cabe determinar a esfera de atividade à qual o poder se refere ou a esfera do poder.

8 "El poder es la capacidad relacional que permite a un actor social influir de forma asimétrica en las decisiones de otros actores sociales de modo que se favorezcan la voluntad, los intereses y los valores del actor que tiene el poder".
} 
O poder simbólico como poder de constituir o dado pela enunciação, de fazer ver e fazer crer, de confirmar ou de transformar a visão do mundo e, deste modo, a ação sobre o mundo, portanto o mundo; poder quase mágico que permite obter o equivalente daquilo que é obtido pela força [...]. O que faz o poder das palavras e das palavras de ordem, poder de manter a ordem ou de a subverter, é a crença na legitimidade das palavras e daquele que as pronuncia, crença cuja produção não é da competência das palavras (BOURDIEU, 2000, p. 14-15)

Importa compreender que os conceitos relacionados ao poder - e à comunicação também - são móveis e apresentam divergências. Contudo, o poder sempre implica pactos e disputas e, também, sempre está ligado à construção da realidade. O lugar de poder que um sujeito ocupa coloca o exercício permanente de uma disputa organizada, centrada, fechada. A questão da disputa é da natureza da política, assim como o poder é da natureza da política e da comunicação. Ainda, cabe ressaltar que o poder não pode ser avaliado em si, pois sempre se estabelece em relação a alguma coisa, e que as relações de poder são as relações que fazem o poder.

Geralmente, pensando uma situação de enfermidade, de certa forma, o que se observa é um enfraquecimento do poder, em virtude de uma possível restrição nas capacidades de agir, além da instabilidade pelo medo do futuro e o assombro da morte. Contudo, no que se refere à produção de efeitos, se se considerar os discursos e suas possibilidades simbólicas, pode-se manter essa capacidade praticamente inabalada. Apesar de não ser o único agente, a construção da realidade - no caso analisado, bem como em outros semelhantes - passa por meio dessa elaboração que pode ter participação tanto da mídia, quanto de outras instituições, como os médicos ou o governo cubano, tomando a situação de Chávez.

Para Foucault (2002, p. 8), "o que faz com que o poder se mantenha e que seja aceito é simplesmente que ele não pesa só como uma força que diz não, mas que de fato ele permeia, produz coisas, induz ao prazer, forma saber, produz discurso". De acordo com o autor, o poder precisa ser considerado muito além de uma instância negativa, com finalidades de repressão, deve ser tomado como uma rede produtiva que atravessa toda a sociedade. Segundo algumas de suas colocações, considera essa perspectiva redutora, insuficiente e talvez até perigosa, e afirma que, se os mecanismos fossem apenas repressivos, provavelmente se originaria um poder muito frágil.

Ainda, sobre "esta coisa tão enigmática, ao mesmo tempo visível e invisível, presente e oculta, investida em toda parte", Foucault (2002, p. 75) elucida que o poder não possui um dono, um titular. O poder se exerce em determinada direção, com sujeitos de um lado e de outro, "não se sabe ao certo quem o detém, mas se sabe quem não o possui" (idem). Apesar de o poder ter certo controle com as relações que se estabelecem, essa capacidade é condicionada, 
não determinada. Dessa maneira, convém referir que onde existe poder, há também resistência que pode resultar em lutas e, inclusive, em inversões de poder.

Prosseguindo às definições do conceito, do ponto de vista sociológico, nas reflexões de Weber (1994, p. 33), "poder significa toda probabilidade de impor a própria vontade numa relação social, mesmo contra resistências, seja qual for o fundamento dessa probabilidade". Portanto, não se limitaria a nenhuma circunstância social específica, dado que a imposição da vontade de alguém pode ocorrer em inúmeras situações. O poder não teria, assim, uma forma definida, mas apareceria e se conformaria ligado às estruturas, sendo que a concepção de sociedade, elaborada pelo autor, implica a separação de esferas (econômica, religiosa, política, jurídica, social, cultural), cada uma com lógicas próprias de funcionamento.

Ainda, considerando as elaborações de Weber (1977, p. 683, tradução nossa) acerca das divisões do poder na comunidade entre classes, estamentos e partidos, pode-se trazer que a ambição pelo poder vai além de manifestações que buscam vantagens econômicas, "pois o poder, inclusive o econômico, pode ser avaliado 'por si mesmo', e com grande frequência a aspiração por

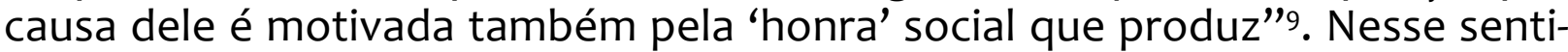
do, percebe-se uma relação que é estabelecida entre prestígio e poder, sendo que haveria atuação mútua nos efeitos, podendo um constituir a base do outro. Convém referir que

os meios utilizados para alcançar o poder podem ser muito diversos, desde o emprego da simples violência até a propaganda e o sufrágio por procedimentos rudes ou delicados: dinheiro, influência social, poder da palavra, sugestão e engano grosseiro, tática mais ou menos hábil de obstrução dentro das assembleias parlamentares $^{10}$ (WEBER, 1977, p. 693, tradução nossa).

Tal perspectiva aponta, segundo Weber (1994), que o poder estaria relacionado à dominação ("autoridade"), partindo da ideia de obediência dentro de determinado grupo de pessoas (os Estados, por exemplo, devem ser obedecidos). A situação pode se basear nos mais diversos motivos de submissão e se estabelece pela presença efetiva de alguém que manda em outros. O autor afirma que os modos de dominação são distintos em suas finalidades e exercícios, mas enfatiza que todos têm em comum a busca pela crença em sua legitimidade.

9“Pues el poder, inclusive el económico, puede ser valorado 'por sí mismo', y con gran frecuencia la aspiración a causa de él es motivada también por el 'honor' social que produce” 10 "Sus medios para alcanzar el poder pueden ser muy diversos, desde el empleo de la simple violencia hasta la propaganda y el sufragio por procedimientos rudos o delicados: dinero, influencia social, poder de la palabra, sugestión y grosero engaño, táctica más o menos hábil de la obstrucción dentro de las asambleas parlamentarias" 
Pode-se perceber que Weber e Foucault diferem na abordagem do poder. Nessa direção, reconhecendo a importância de ambos para tais teorizações, importa pontuar que, nesse texto, são mais evidentes as aproximações com o primeiro. Assim, considerando a proposta de problematização, dentre as classes de dominação legítima ${ }^{11}$ de caráter racional, tradicional e carismático, a que mais interessa a esse texto é a última, "baseada na veneração extracotidiana da santidade, do poder heroico ou do caráter exemplar de uma pessoa e das ordens por esta reveladas ou criadas" (WEBER, 1994, p. 141). A relação com a subjetividade, com o valor institucional atribuído a uma determinada pessoa, a obediência ao líder qualificado dentro da crença, da confiança no carisma, remete ao caso do governo venezuelano representado pela figura do "líder" Hugo Chávez.

Traços de uma personificação do poder são delineados por Schwartzenberg (1978), quando afirma que, hodiernamente, o poder ganha vida, humanização, adquire fisionomia (do dirigente que o exerce), pelo que seria a figurativização da política. O processo ocorre por haver uma identificação, um reconhecimento do personagem com o grupo no qual exerce o poder. $O$ dirigente acaba se impondo pela sua popularidade, por seu prestígio junto aqueles que "governa"; ele figura, representa o poder sob uma forma visível, corporifica uma noção abstrata, atribuindo-lhe aspecto humano e material.

Outro aspecto importante da questão trazida por Weber (1994), diz respeito à reinterpretação antiautoritária do carisma. Se originalmente o princípio carismático de legitimidade tinha sentido autoritário, após ser reinterpretado, passou a antiautoritário, especialmente em virtude do reconhecimento conferido pelos dominados à autoridade que, além de qualificada pelo carisma, é também legitimada. Novamente há aproximações com a situação do presidente da Venezuela que, apesar de muitas vezes ser acusado e representado como ditador, exerce a posição que lhe foi conferida por meio do voto do povo de seu país, em um processo eleitoral legítimo.

Para uns, o déspota. Para outros, o libertador. Chávez sempre foi muito mais complexo que as dualidades e os maniqueísmos nos quais se tenta encaixá-lo. A partir desses sentidos, justamente, é que se manifestam as semelhanças com o "herói" teorizado por Schwartzenberg (1978). Uma figura mítica com que os homens da política sonham se tornar. Um sujeito dotado de extraordinários atributos, predisposto à conquista e à glória, beirando o sagrado, no limiar entre o céu e a terra. O enviado para salvar, redimir, liderar e libertar os seus através de todo poder e autoridade.

As palavras de Schwartzenberg (1978, p. 14) parecem exageradas afirmando que "mais que qualquer outro dirigente, o herói é um show-man, um homem de espetáculo [...]. Sobressaindo da monotonia da autoridade de ro11Cabe ressaltar a compreensão de que essas classes de dominação não ocorrem de maneira "pura", tal divisão serve mais como artifício pedagógico que como fixação do conceito. A elaboração dessas perspectivas pode ser encontrada em Weber (1994), principalmente na página 141 e seguintes 
tina, é o homem-orquestra, o homem-prodígio, o homem-festa. Sempre em representação". Todavia, buscando ilustrar a reflexão, basta mencionar uma atitude do presidente venezuelano, ocorrida no dia 7 de janeiro de 2002, e descrita por Maringoni (2004). Na ocasião, em frente às câmeras de televisão do programa Alô Presidente, munido de um apito e da expressão off-side (típica no beisebol, para indicar que um jogador está fora da partida), Hugo Chávez dispensou sete gerentes da empresa Petróleos de Venezuela (PDVSA).

A perspectiva de Schwartzenberg (1978) pode ser considerada similar à de Balandier (1982, p. 7), para quem, a teatralidade da política é ainda mais acentuada por esse mito do herói, que engendraria uma autoridade mais espetacular que a rotineira. O herói "é reconhecido em virtude de sua força dramática [...]. Ele aparece, age, provoca a adesão, recebe o poder. A surpresa, a ação, e o sucesso são as três leis do drama que lhe dão existência".

Entretanto, é fundamental destacar que nem todas as características dessa teoria do herói cabem a Chávez. O segredo e a distância, por exemplo, não parecem fazer parte de seu modo de figurar. A ocupação de espaços em que a manifestação do povo é praticamente livre e nos quais se estabelecem certas possibilidades dialógicas, como o Twitter e o próprio programa Alô Presidente, poderiam assinalar um interesse em ter acesso e conhecer a outras falas, plurais e, talvez até, divergentes.

Acerca da postura do homem político, Schwartzenberg $(1978$, p. 6) afirma a necessidade de concordância em desempenhar o personagem a que está relacionado, de maneira duradoura. É preciso que ele aceite "ajustar-se à imagem de si mesmo divulgada pela propaganda [...]. Pois o que vale é a produção de mitos e de símbolos. Ainda que sem relação exata com a realidade". Mas se algo escapar do controle? A "marca", o "produto", pode continuar imutável?

Simplificadamente, o caso da doença do presidente venezuelano, no portal TeleSUR, trouxe discursos preocupados, porém otimistas e esperançosos, que pouco modificaram a imagem de Chávez, anterior ao diagnóstico. Em geral, buscava-se explicar a situação, principalmente tranquilizando o povo de que os procedimentos necessários haviam sido feito, como é apresentado na sequência.

\section{MÍDIA E DOENÇA: A IMAGEM DE CHÁVEZ NO PORTAL TELESUR}

Conforme mencionado, o objetivo desse texto é problematizar o modo como a imagem do presidente Hugo Chávez foi abordada, pelo portal TeleSUR, nas notícias referentes à situação de sua saúde. Considerando a doença como um elemento da esfera privada, questiona-se o modo como assumiu o espaço público, construindo imagens acerca dessa figura da política.

Tomando o portal do sistema comunicativo TeleSUR e as notícias caracterizadas, uma primeira constatação que se pode colocar diz respeito ao mo- 
mento em que as informações de alerta surgiram e à maneira como os fatos foram ganhando amplitude e espaço nessa mídia. No dia 10 de junho de 2011, quando se falou pela primeira vez, através de um comunicado lido pelo chanceler venezuelano, Nicolás Maduro, acerca do abscesso pélvico ${ }^{12}$ encontrado em Chávez, a operação para retirada já havia sido realizada, em Havana, com êxito segundo a TeleSUR. Na sequência, algumas notícias foram divulgadas, explicando o problema e as razões que levaram à cirurgia, mas principalmente ressaltando que o presidente estava bem, recuperando-se e cumprindo todas as suas funções e responsabilidades.

Durante cerca de duas semanas, as notícias trazidas pelo portal sobre o estado do presidente eram escassas, superficiais e traziam poucas novidades, referiam-se apenas a visitas (como a de Fidel e Raúl Castro, no dia 18 de junho' ${ }^{13}$ ) e enfatizavam sempre o restabelecimento de sua saúde. Enquanto isso, em outros espaços midiáticos, inúmeras especulações estavam sendo feitas, inclusive preconizando a morte de Chávez.

No dia 26 de junho, o portal apresentou matéria ${ }^{14}$ na qual o presidente da Assembleia Nacional da Venezuela, Fernando Soto Rojas, negava informações, veiculadas por outras mídias, acerca de que o presidente estaria com câncer. De certa forma, a manifestação aumentou as dúvidas e inquietações sobre a real situação de enfermidade do governante. Para muitas pessoas, a negação de Rojas confirmava algo de errado com o bem-estar de Chávez, e aumentava o clima de tensão em virtude da posição quase messiânica que o dirigente ocupa.

Dessa maneira, possivelmente para acalmar os ânimos, em 28 de junho, o portal TeleSUR trouxe imagen ${ }^{15}$ de uma reunião realizada entre o presidente da Venezuela e o líder e ex-mandatário cubano, Fidel Castro, caminhando e conversando, em Havana. Utilizando artifícios como a tomada de um jornal impresso diário, segurado pelas mãos de Chávez, o vídeo e as fotografias serviram para atestar que o Chefe de Estado estava realmente vivo e, apesar de 12Após passar duas semanas em repouso, devido a uma lesão no joelho, Chávez estava retomando normalmente as atividades. Em viagem pelo Brasil e Equador, sentiu um mal-estar e, depois de exames, foi diagnosticado o abcesso e constatada a necessidade de uma cirurgia corretiva, realizada em Havana, no dia 10 de junho de 2011. Geralmente causado por uma infecção bacteriana, o abscesso é um acúmulo de inflamação. O portal de TeleSUR traz mais informações:<http://www.telesurtv.net/secciones/noticias/93977-NN/-iquestque-es-un-absceso-pelvico/>.

13 “Fidel y Raúl Castro visitaron al presidente Chávez". Disponível em: <http://www.telesurtv. net/secciones/noticias/94231-NN/fidel-y-raúl-castro-visitaron-al-presidente-chávez/>.

Acesso em: 8 ago. 2011.

14 "Presidente de Parlamento de Venezuela desmiente que Chávez padezca de câncer". Disponível em: <http://www.telesurtv.net/secciones/noticias/94548-NN/presidente-de-parlamento-de-venezuela-desmiente-quechávez-padezca-de-cáncer/>. Acesso em: 8 ago. 2011. 15"Presentan imágenes de presidente venezolano Hugo Chávez en reunión con Fidel Castro". Disponível em: <http://www.telesurtv.net/secciones/noticias/94638-NN/presentan-imagenes-de-presidente-venezolano-hugo-chavezาen-reunion-con-fidel-castro/>. Acesso em: 8 ago. 2011. 
estar mais magro e com a aparência abatida, parecia estar em processo de restabelecimento.

Dois dias depois, surgiu a notícia ${ }^{16}$ do tumor cancerígeno através de um extenso comunicado do próprio Hugo Chávez. Para desenvolver o acontecimento, são elaboradas matérias que enfocam a enfermidade por meio de significados relacionados ao âmbito profissional de um mandatário (a oposição se manifestando pela saída de Chávez, os apoiadores ocupando as ruas, enviando sua solidariedade). Também se observa uma construção por meio de informações da esfera pessoal, apresentando o mandatário como um sujeito social semelhante aos demais (representada especialmente pela visita da família, pelo apoio dos amigos e pela fé, esperança e gratidão a Deus).

Partindo dessa perspectiva, importa enfatizar o poder que a mídia apresenta na capacidade de dar espaço e visibilidade aos outros poderes, e também na possibilidade de que, por meio de seus discursos, os outros discursos sejam abrigados, divulgados e, inclusive, legitimados. Nesse sentido, além dos discursos da Presidência, em geral, as notícias traziam muitas falas do próprio Chávez, tanto no papel de governante, comprometido com o povo e responsável pelo país, quanto no de paciente, inseguro e fragilizado frente às incertezas de seu bem-estar.

Com relação aos discursos acionados pelo portal TeleSUR, chamou atenção, ainda, aqueles procedentes do líder Fidel Castro. Nessas falas, o cubano assume as posições de amigo, conselheiro, médico, apoiador, mandatário, entre outros. Em geral, aparecem palavras de incentivo e otimismo sobre o estado de saúde do companheiro de política e ideologia.

As demais informações enfatizam a manutenção do presidente Chávez no poder, através de comunicados de solidariedade dos governantes da região e de manifestações de apoio da população venezuelana. Também a presença do governante, apesar da enfermidade e dos procedimentos de recuperação, passa a ser mais intensa depois da notícia do tumor, ocupando os espaços principais do portal, com imagens, vídeos, entrevistas, reportagens, e similares.

No que diz respeito a esses pontos de vista, acredita-se que o portal TeleSUR, de certa forma, participou da manutenção de certos interesses do governo da Venezuela, mantendo a discrição sobre determinadas questões da enfermidade do presidente e, especialmente, evitando informações sem respaldo, pela mera especulação, como foi visualizado em alguns espaços midiáticos. Contudo, não se pode afirmar que essas posturas tiveram relação direta entre o Estado venezuelano e os agentes responsáveis por essa mídia.

16"Chávez anuncia que se está recuperando satisfactoriamente de una lesión cancerígena”. Disponível em:<http://www.telesurtv.net/secciones/noticias/94733-NN/chávez-anuncia-que-se-está-recuperando-satisfactoriamente-de-una-lesión-cancerígena/>. Acesso em: 8 ago. 2011. 


\section{CONSIDERAÇÕES}

Importa colocar que, mesmo com a situação de instabilidade e incertezas quanto à saúde de Hugo Chávez, o portal TeleSUR procurou manter o equilíbrio informativo, participando de maneira significativa dos movimentos e elaborações. Todavia, em algumas ocasiões, faltavam informações e esclarecimentos aos públicos, principalmente, considerando a inconstância das notícias e o clima de curiosidade instaurado, devido às suposições apresentadas por outras mídias, chegando, por exemplo, a mencionar complicações no estado do presidente e seu falecimento.

No que se refere à imagem de Chávez frente ao poder da Venezuela e ao espaço que ocupa como líder na América Latina, apesar de uma alteração inicial ter colocado a fragilidade, a insegurança e o temor do presidente, na continuidade das notícias, observa-se a manutenção dos mesmos formatos presentes nos discursos anteriores à enfermidade. O governante continua sendo apresentado com sua firmeza, postura decidida e determinação nas decisões que toma, também por seus pronunciamentos ácidos e polêmicos, e pelas relações com os Chefes de Estado da região. A imagem de herói permanece, de certa maneira, inabalada.

Entretanto, as relações entre poder e mídia são bem mais complexas que os aspectos pontuados por esse artigo. Uma compreensão plena da cobertura da enfermidade do presidente Hugo Chávez no portal TeleSUR passaria pela retomada das notícias divulgadas e análise desse material através de uma metodologia pertinente, segundo as necessidades do problema/objeto de pesquisa.

Dessa maneira, as reflexões estabelecidas a partir desse texto contribuíram mais para elaborar questionamentos que para sanar inquietações. As dúvidas que surgem se referem aos modos de representação do poder e da doença, nos espaços midiáticos, principalmente, os brasileiros, pelo fato de haver outros presidentes da América Latina que passaram por diagnósticos de câncer, conforme foi referido. Também, colocaram-se indagações acerca do modo como os representantes políticos constroem sua própria imagem nos espaços que são de seu domínio, como é o caso do Twitter, de modo especial, em situações de crise e instabilidade.

As bases para a elaboração teórica e reflexiva desses momentos, certamente, podem ser fixadas a partir das obras e autores de referência com os quais se teve contato na disciplina e durante a produção desse artigo. Os caminhos possíveis assinalam a busca por aprofundamentos acerca dos conceitos e teorizações que foram acionados e, ainda, a reflexão sobre outras oportunidades de construção, de acordo com a solicitação dos objetos e problemas desenvolvidos. Agitações interrogativas passíveis de se problematizar, em futuras processualidades de investigação, e que contemplem as instâncias evidenciadas na disciplina e essa inter-relação intrínseca existente entre a sociedade, a comunicação e a política. 


\section{REFERÊNCIAS}

ALMEIDA, Jorge. Marketing político: hegemonia e contra-hegemonia. São Paulo: Fundação Perseu Abramo; Xamã, 2002. BALANDIER, Georges. O poder em cena. Brasília: Universidade de Brasília, 1982.

BOBBIO, Norberto et al. Dicionário de política. 12.ed. Brasília: Universidade de Brasília, 2002. Vol. 2. BOURDIEU, Pierre. $O$ poder simbólico. 3.ed. Rio de Janeiro: Bertrand, 2000.

CASTELLS, Manuel. Comunicación y poder. Madrid: Alianza, 2010.

FOUCAULT, Michel. Microfísica do poder. 17.ed. Rio de Janeiro: Graal, 2002.

GOMES, Wilson. Transformações da política na era da comunicação de massa. São Paulo:

Paulus, 2004.

MARINGONI, Gilberto. A Venezuela que se inventa: poder, petróleo e intriga nos tempos de Chávez. São Paulo: Fundação Perseu Abramo, 2004.

SCHWARTZENBERG, Roger-Gérard. O estado espetáculo. Rio de Janeiro: DIFEL, 1978.

WEBER, Max. Economia e sociedade: fundamentos da sociologia compreensiva. 3.ed.

Brasília: Universidade de Brasília, 1994.

. Economia y sociedad: esbozo de sociología compreensiva. 2.ed. México: Fondo de

Cultura Económica, 1977.

WEBER, Maria Helena. Comunicação e espetáculos da política. Porto Alegre: Editora da

Universidade, 2000. 


\section{Tabita Strassburger}

Mestre pelo Programa de Pós-Graduação em Ciências da Comunicação da Universidade do Vale do Rio dos Sinos (UNISINOS). Graduada em Comunicação Social - Jornalismo pela Universidade Federal de Santa Maria (UFSM). Integrante do Grupo de Pesquisa Processos Comunicacionais: epistemologia, midiatização, mediações e recepção - PROCESSOCOM (CNPq/CAPES/UNISINOS) e da Rede Temática de cooperação Comunicação, Cidadania, Educação e Integração da América Latina (Rede AmLat). 